This is an Accepted Manuscript of an article published by Taylor \& Francis in International Journal of Heritage Studies on 19 Apr 2020, available online: https://doi.org/10.1080/13527258.2020.1752772

\title{
Rethinking Game Heritage — Towards Reflexivity in Game Preservation
}

\author{
Niklas Nylund ${ }^{\mathrm{a} *}$, Patrick Prax ${ }^{\mathrm{b}}$ and Olli Sotamaa ${ }^{\mathrm{a}}$ \\ ${ }^{a}$ Faculty of Information Technology and Communication Sciences, Tampere University, Tampere, \\ Finland; ${ }^{b}$ Department of Game Design, Uppsala University, Visby, Sweden
}

Niklas Nylund is a museum researcher and curator working for the Finnish Museum of Games in Tampere, Finland. He is also working on a $\mathrm{PhD}$ on videogame heritage issues at the Centre of Excellence in Game Culture Studies at the University of Tampere. His research interests include game preservation, game history, exhibition design and questions of cultural heritage and inclusivity.

Patrick Prax is Assistant Professor at the Department of Game Design at Uppsala University. He has a $\mathrm{PhD}$ in Media Studies from Uppsala University and wrote his dissertation on the co-creation of digital games as alternative media. In a research project at the Swedish National Museum of Science and Technology Patrick investigated the preservation and exhibition of digital games and appears in the newly opened exhibition Play beyond Play as an expert on participatory media and games. He is also serving as board member for the Cultural Heritage Incubator of the Swedish National Heritage Board.

Olli Sotamaa, PhD, is Associate Professor of Game Culture Studies at Tampere University. His publications cover user-generated content, player cultures, player-centred research methods, and cultural and historical analysis of game industry. His work has been published in several scholarly journals including e.g. Convergence, Fibreculture, First Monday, Games and Culture, Game Studies, International Journal of Arts and Technology, International Journal of Cultural Policy, and Simulation and Gaming. He's a co-lead of Tampere University Game Research Lab and a team leader at the Centre of Excellence in Game Culture Studies (2018 - 2025). 


\section{Rethinking Game Heritage — Towards Reflexivity in Game Preservation}

While games and the cultures that have sprung up around them are diverse and vastly different from each other, most exhibitions dealing with them are based on a limited understanding of games that relies on symbolic brands on one hand and on the centrality of playable experiences on the other. This bias is potentially replicated by heritage institution collections starting to define how games become cultural heritage. While games research has shown that games are firmly nestled in a participatory grassroots culture, these kinds of perspectives are curiously lacking in exhibitions. By connecting previous work on critical and intangible heritage with game studies literature, this paper emphasises the importance of various productive communities for game heritage. The concepts of intangible and critical heritage suggest that the inclusion of players and communities into the game heritage process could offer a more diverse heritage discourse. But participatory practices in collector run museums tend to produce game heritage which is implicitly working towards the same kind of one-sided understanding of games that has been criticised heavily in game studies. The critical expertise of museum professionals is needed in order to start incorporating the varicoloured practices of communities into our understanding of game heritage.

Keywords: Game preservation, intangible heritage, participatory heritage, critical heritage, game culture, game studies

\section{Introduction}

In the past decade, video games have increasingly found their way into museums and exhibitions, highlighting the increasing cultural value associated with games and the institutionalization of game culture. While games come in many forms and spawn manifold subcultures, communities, and participatory networks, digital game heritage work does not always reflect this diversity. Instead, based on our observations over the years, it often relies heavily on the dominant perspective provided by one particular demographic, specifically young and middle-aged white male gamers. While the biases in exhibiting digital games are not the same across all museums, locations, and foci, in most cases we can identify exaggerated centrality of well-known game brands from the international game industry, a focus on 'original experiences’ as in un-modified and unchanged games played on original hardware, and the 
inclusion of symbolic characters, games, platforms, and companies as recurring elements. These elements are often replicated both by established museum exhibitions and by hobbyist collections worldwide, and potentially also by heritage institutions and their collections, which are starting to define what elements of games should constitute cultural heritage.

From the perspective of cultural heritage research, this all may not be that surprising. Previous work in this field has criticised the way heritage is used as a means for politics and developed a number of critical interventions (Smith 2006). Conversely, early game preservation research has to a large extent been dealing with ontological questions related to games in information systems (e.g. Delve, and Anderson 2014), or technological questions related to keeping games playable (e.g. Guttenbrunner, Becker, and Rauber 2010; Pinchbeck et al. 2009), without touching upon the ideological questions related to how games and play cultures should be dealt with as heritage. In addition to the high-polish surfaces of international triple- $\mathrm{A}^{1}$ games, we feel that also issues like local game cultures, non-commercial and participatory game development, as well as problematic use, exploitation of game workers, and bigoted representations of women and minorities, in short the dark heritage of games, should be discussed as inseparable parts of game heritage. While there is some previous work that is pointing at the central importance of the cultural context in which games are made, played, and re-made, with all the baggage that entails (Sköld 2018; Nylund 2018; Guins 2014; MacDonough et al. 2016; Barwick, Dearnley, and Muir 2011, Swalwell 2013), games heritage as a field of research has not yet emerged. By connecting relevant game studies theorizations with previous work on critical and intangible heritage, this paper aims to emphasise the importance of diverse productive game cultural activities and play communities for game heritage.

The paper draws from various perspectives including first critical heritage studies (Smith 2006), second the concept of intangible heritage (Smith and Akagawa 2008), third games as participatory, spreadable and co-created culture (Jenkins 2006; Jenkins, Ford, and Green 2018), fourth recent work on exhibiting and preserving gaming communities (Nylund 2018; Sköld 2018), and fifth the role of institutions and other stakeholders as gatekeepers in heritage issues (Coleman 2015). The discussion will help us reach a new understanding of what kinds of interventions would be needed in order to diversify our understanding of game heritage and what kinds of actions various stakeholders would need to do in order to reach these goals. 
The paper is part of museum working practices research (MacLeod 2001), as it is using relevant examples from recent game museums and their exhibitions, as well as the experiences of the authors who have worked at the Finnish Museum of Games, and the National Swedish Museum of Science and Technology. The examples used are not meant to be representative of all kinds of game preservation but instead aim to illustrate certain theoretical points. The aim of the paper is to bring these different approaches together to help heritage institutions reflect on their practices when they are starting to produce game heritage with their long-term collection management policies. The critical analysis of the stakeholder power positions involved in defining game heritage is also related to the normative aim of democratizing and broadening the 'cultural heritage process'.

\section{Games as cultural heritage}

The reduction of the past into a specific narrative that sidelines alternative presentations has in heritage research been explored through the notion of the 'authorised heritage discourse' (AHD) (Smith 2006), which is defined as a social construct with the aim of supporting a particular political claim for power. The AHD tends to produce a monolithic, unchanging view of the past by not providing real opportunities of interacting with it. It places us, the current generation, as its guardians, but does not allow us to be critical of what this heritage is, and aims to ground its existence in the sheer materiality of the sites and objects it aims to preserve, by the 'selfreferential nature of the discourse, which continually legitimises itself and the values and ideologies on which it is based" (Smith 2006, 30).

The notion of the AHD was originally developed as a critical response to the way in which Australian heritage institutions have been marginalizing indigenous populations and their heritage in the process of legitimizing the colonial appropriation and domination of the land. This AHD is intertwined with ideas of nationality, modernity, and traditional Western values, and it conversely sees museums as institutions that are preserving and conserving this very same claim to power. In this setting, heritage institutions and museum professionals, who use their power positions to maintain the status quo by their 'disciplinary authority and identity' (Smith 2006, 51), are a tool of the powerful for delegitimising the marginalised.

The concept of the AHD makes the political aspects of heritage work openly visible, and therefore provides a useful starting point for discussing digital games as cultural heritage. It can 
also help us understand the mechanisms by which the dominant notion of heritage is constructed and how possible alternatives and countermeasures can be created. While game preservation research (e.g. Lowood et al. 2009; Newman 2012; Guins 2014) has sometimes been dealing with similar issues, it has rarely made an explicit connection to critical heritage studies. Maybe the most explicit connection is Swalwell's (2013) work in which she has been criticizing the 'authorised' position of ‘original experiences', propagated mostly by the retrogaming and game collecting communities.

In order to discuss the games-specific AHD in detail, we first need to understand the nature of intangible heritage. UNESCO $(2003,3)$ defines intangible heritage as 'the practices, representations, expressions, knowledge, skills’ that communities recognise as part of their cultural heritage. Cultural heritage research has highlighted that one of the central objectives of heritage is the preservation of and communication about the practicalities of human life and the human condition (Smith and Akagawa 2008). While tangible heritage sites and objects might be easy to list (e.g. Stonehenge, Angkor Wat, Mona Lisa), places and objects like this are not inherently valuable, and they do not contain any 'innate meaning'. Museums and other heritage institutions do not simply 'find' valuable heritage sites in the world, but rather make them (and thus protect them) as part of their operations (Carman 2010). What makes these sites and objects valuable (or 'heritage') are the 'present-day cultural processes and activities that are undertaken at and around them' (Smith 2006, 3).

The point that Smith makes, is that tangible and intangible heritage are in the end two sides of the same coin. Understanding 'all heritage as inherently intangible' (Smith 2006, 3) makes it clearer for heritage institutions that instead of only things, sites, and objects, they should focus on ideas, values, ethics, cultural practices, and larger societal framings. In the game heritage context, the concept of intangible heritage can be used to deal with the mostly nonphysical aspects of games and play, for example the ways players interact with games and each other, and even the different communal practices and networks that spring up around and in connection to games. This brings us to contemporary game studies and the interrelation of the game and player.

Digital games are obviously not only about hardware and software - instead they only come to life as they are played. While 'there is no game without a player’ (Ermi and Mäyrä 2005, 16), at the same time 'players cannot exist without a game they are players of' (Aarseth 2007, 
130). The central role of the player in actualizing the game may not be unique for games, but arguably the input of players during play goes beyond active reading and meaning-making that can be found in connection with any kind of media text (Barthes 1977). Games are interesting for museums and exhibitions, since it is theoretically possible to allow visitors to become players themselves, so that they can re-define what the game is by playing it. This allows future generations to explore games and potentially recreate them in their own way, and it is the approach that has made game exhibitions focused on playable games so popular worldwide.

On the surface level, it seems that games, especially when exhibited as playable games, automatically give the power to re-define the meanings of them as cultural heritage to the players and visitors in the museum. However, the focus on 'play as activity' for an understanding of what games are is deeply problematic. It is impossible to exhibit a game and expect it to stand for all the varying practices of play, since playing is always context bound (e.g. Nylund 2018), and actually understanding the cultural meaning making processes of past games might be impossible, especially with games that require some kind of cultural knowledge that most present museum visitors lack. This is obviously not just a characteristic and a challenge of game-focused museum efforts but of museum efforts generally (c.f. Greenhill 1992), but it is an issue highlighted by the reliance on play as a central exhibition focus in game exhibitions worldwide.

While games outside of museums are played by 'many if not all ages, genders, sexualities, races, religions, and nationalities' (Shaw 2010, 416), and different players and 'playings' have vastly diverging practices of meaning-making that emerge in the interaction between player activities and the characteristics of the digital game being played, playing games inside an exhibition does not automatically communicate the socio-cultural importance and meaning that other players created with it, which made the game relevant and important to be preserved in the first place. Still, the focus on games as activity has been a standard feature in game exhibitions, at least since the success of Game $\mathrm{On}^{2}$, a Barbican International Enterprises produced touring exhibition, which has since been set up around the world in at least dozens of countries.

While game heritage, and the museums dealing with it, are getting more institutionalised in the sense that they have permanent staff and professional-looking exhibitions, what they are often lacking is critical curatorial engagement with their subject matter. This might be because their background is often in private collections that have turned into actual permanent museums 
over time (e.g. National Videogame Museum in the USA ${ }^{3}$ ), they act as public fronts for the game industry (e.g. Nexon Computer Museum in South Korea ${ }^{4}$ ), or because they are grounded in the tourism industry rather than in critical heritage practices (e.g. the Stockholm Game Museum in Sweden $^{5}$ ). While the founders of these museums might have massive amounts of knowledge and great love for their subject matter, that might actually make it harder for them to engage with game heritage in a more critical manner.

However, the most relevant limitation of play as a mode of engaging with games as intangible cultural heritage is not that the same game can be played in different ways but that intangible heritage is related to community. Different studies of games and their players have shown that games exist within a broader gaming culture that extends beyond the games themselves (Sotamaa 2009; Taylor 2009). Instead of conceiving games as a self-governing cultural sphere, they are better understood as a part of culture, 'games in culture' (Shaw 2010, 416). Some recent accounts have that scholarly attention needs to be shifted from merely games to the diverse forms of play (Sicart 2014) or the texts, practices and institutions that envelope games (Consalvo 2017). In heritage research, intangible heritage is understood to be part of the cultural processes and activities where meanings are given to tangible objects. This meaning is shared in a community, so playing a game alone in an exhibition setting without other layers of contextualization is not enough to communicate the socio-cultural relevance of it, or to show the varicoloured practices of the community that had developed around it (Prax et.al. 2016). For that

reason, Newman (2012, 122 - 123) has proposed changing the focus of game preservation efforts from games as artefacts to play as activity.

\section{Participatory games, participatory preservation}

Games, not just in the digital sense, but also as a more far reaching and historical activity, have always been participatory - communally created, modified and designed (Parlett 1999). Recent literature has highlighted how player creators are as central in the creation of digital games today as they have been for past types of games (Prax 2016). While games have become proprietary commodities, they are still co-created, and in many cases players' creative contributions are crucial for the success of particular games. Player-created content has spawned massive communities with examples like streaming (Sjöblom et al. 2019), or esports (Hamari and Sjöblom 2017), which not only potentially subvert the meanings of games, but even co-create 
them (Prax 2016). These practices are further complicating questions of authorship and ownership, to the point that research is dealing with co-created games as a form of exploitation of the free labour of precarious participants (Banks and Deuze 2009; De Peuter 2011; Fuchs 2010; Kücklich 2005; Postigo 2016; Sotamaa 2007). Game culture and communities engage in practices like the writing of fan fiction, the organization of wikis, recording of Let's Play videos and guides, programming of mods, and sewing of cosplay costumes, which have rarely been dealt with in game preservation literature (Sköld 2018) or exhibitions. At the same time, in digital game exhibitions, player creators rarely hold centre stage, although the importance of player generated content and modding has been highlighted in game preservation literature (Newman 2012; Sköld 2018).

Here the intervention of critical heritage merges with critical games research, as both emphasise the importance and authorship of player participants. There is a need to include disempowered groups and minorities into the curatorial processes of game museums in a way that makes it possible for them to stand up for their understanding of their own culture, and in a way that justifies their participation in the co-creation of the actual games. Exhibitions (and collections) are part of an ongoing struggle over the power of who gets to define how games are seen as heritage, so questions of representation of minorities and women, and the exploitation of vulnerable players and game workers, should have a part in them. The cultural struggle between different groups in the game community (e.g. Gamergate ${ }^{6}$ ) for example are relevant for understanding the way game cultures interact with the current zeitgeist. Leaving out this kind of dark heritage means running the risk of misrepresenting game heritage.

The inclusion of the relevant participants in the preservation of immaterial cultural heritage has been explored to some extent in previous work. Newman (2009; 2011; 2012) has drawn attention to the ways in which players are interacting with games and modding them, as well as to the ways that they are documenting their own activities. The latter is true of a plethora of games like Animal Crossing, The Sims and Katamari Damacy (Newman 2009), where players might be tempted to collect the various in-game artefacts and systematically index those as a form of collection management, but also of the behaviour of many player-collectors, who take this kind of collecting behaviour to the physical realm by collecting games and their assorted ephemera. This kind of player activity is a first step towards managing game heritage, as in-game collecting also leaves various documentary 'traces' (Sköld 2013) by the behaviour of players and 
player communities, as does physical collecting and the collection management presence of online collectors. This is perhaps best exemplified by the practice of walkthroughs, which are player written texts that explain the contents games and what is needed in order to successfully play them, thus showing games as 'rules and systems in and at play' (Newman 2011, 122).

The work of Swalwell, Ndalianis, and Stuckey (2017) and Stuckey et al. (2015) show how player creators can become participants in the preservation of games and game culture also on the institutional level. While there are some limitations to their case studies, mostly that they have been focusing on work with independent game creators and not as much with players and other stakeholders in game culture, their work is showcasing how researchers and game community members can work together to preserve games and game culture. Stuckey et al. (2015) have proposed various participatory working models, ranging from ideas like how the taxonomies used on retrogaming sites can help inform museum work practices and their structures of information and documentation, on to extensive participatory projects, where community generated content is used as the example of how to deal with collections. They have also looked into the participatory nature of game heritage projects, into the ties between collectors and heritage institutions, into how the heritage work done by hobbyists in many ways forms a base for work done by museum professionals, but also on how the hobbyist produced collections (c.f. 'rogue archives'7) have in many cases assembled more complete repositories of information and metadata than actual heritage institutions.

These results can be seen as an example of 'intangible heritage networks' (e.g. Severo and Venturini 2016) in which game heritage is being produced by a wide network of stakeholders, and where the 'cultural heritage community' recreates and nurtures living intangible heritage by working together (Suominen, Sivula, and Garda 2018). At the same time, there seems to be a contradiction between the already participatory reality of the creation of game heritage and the exclusion and biases that still exist in game museums. From the perspective of intangible and critical heritage, the inclusion and empowerment of participants from the practitioners of the respective communities should counteract their marginalization of minorities and offer an alternative to the AHD. In the following, we move on to investigate why this does not seem to be the case for digital game heritage. 


\section{Replication of the AHD and exclusion}

The historiography of games have largely been born, not out of the work of heritage professionals or historians, but rather out of the work done by hobbyist, collector communities, and game journalists (Suominen 2011). While the ‘yearning for old items' and the discussion about how to understand and represent digital game history has to a large extent been born out of game journalism practices and retrogaming ${ }^{8}$ communities, these representations of the experiences of (now) middle-aged white males got added traction because of the Internet, which became the place to organise, among other things, participatory game 'museums' (Suominen, Reunanen, and Remes 2015, 87). This focus on nostalgia also lead to the centrality of iconic symbols such as Super Mario, Pac-Man, or Lara Croft, that can act as powerful triggers for shared nostalgic experiences, even if the players have experienced the games in widely different actual embodied play situations.

The hobbyist communities have been the trailblazers of game heritage preservation and only more recently have various institutional heritage stakeholders, like national libraries, various game preservation initiatives, run by collectors as well as established museums, gotten involved. However, the bias in the exhibition of games seems not to be a result of this shift that Suominen, Sivula, and Garda $(2018,181)$ identify as a shift from ‘non-authorised and selfauthorised' game heritage to 'officially authorised heritage'. The game heritage discussion has not abandoned the discourse produced by game journalists and retrogaming communities, but is rather expanding on it. Thus, the discourse produced by the participants seems to emulate some of the logics of the AHD like the focus on objects, the representation of the past from one monolithic perspective, and the exclusion of minorities.

Writing about how collectors acquire and justify their acquisitions, Belk (1994, 320)

points out how they simultaneously remove objects from the sphere of commodities, and ritually transform them into personally, as well as socially, significant objects. The objects removed from everyday life become 'sacred' objects, with meanings that exceed their utilitarian and aesthetic endowment. This is true for both hobbyist collections and professional museum collections. There are, however, significant differences, too. Hobbyist collecting may sometimes be actually more about accumulating, hoarding and investing (Belk et al. 1991) or about creating 'fetish objects’ (Pearce 1994) that are mostly detached from any context, whereas a professional museum ideally should be more interested in systematic collections, where the socio-cultural 
context and provenance would be more in line with an intangible heritage approach. The contextless approach that collectors utilise still continues, although collectors are themselves a living part of this very context, and would be in an ideal position to document their personal involvement with the objects collected.

Moncunill-Piñas $(2017,5)$ has researched ‘amateur museums’ and noticed how they are simultaneously both 'producers and consumers of their own museographic activity'. By this she means that they are naturalizing the subjects they are dealing with by making them be perceived as natural and unchanging, instead of 'historical and arbitrary'. At the same time, they are empowering themselves to be part of the heritage discourse by giving themselves a voice as amateurs dealing with a professional topic, and thus taking over power positions that enable them to choose whether to break, use, resist, or adapt to the conventions at use in professional museums. Thus, they are both expressing doubts about their museographic expertise, as well as critiquing professional museums (Moncunill-Piñas 2017, 15 - 17). The same kinds of logics can be applied to participatory game heritage work, where amateur museums and collectors are likewise involved in both naturalizing their particular perspective on games, but also empowering themselves by displaying mostly playable content instead of objects behind glass. Amateur game museums and mimic the workings of professional museums in their exhibitions and collections, express doubts on how legitimate their museographic endeavours are, and criticise and distrust professional museums for the lack of playable content and interactivity. This is ironic in a way. While amateur museums rightly distrust professional museums from a perspective of critical heritage, they seem to be mostly concerned about emulating the appearance of a professional museum, which includes a focus on sacred objects and a naturalised vision of heritage, i.e. AHD. Their biggest strength, their alternative approach to heritage and its meanings, seems to be what they are most in doubt about.

Another attribute of an AHD is that it becomes very difficult to propose competing versions of heritage, since the self-referential nature of the discourse 'continually legitimises itself and the values and ideologies on which it is based' (Smith 2006, 30). Game heritage is defined by and for the people included in it, but not by those who are left outside. This process of defining by excluding can be seen in action in the ways 1980s UK game magazines defined the 'gamer identity’ by leaving out certain elements, notably readers' parents, women, and analogue game players (Kirkpatrick 2012). A similar process can be seen in the 1980s Finnish hobbyist 
fanzines dealing with home computers and games, as they are also a stage for competing definitions, and a push for separating the 'real' members of game cultures from those who are seen to not be part of those cultures (Nylund 2016). Given this context, it is easy to see how the symbols and monuments of game heritage are defined by an ongoing negotiation, which makes game cultures, play communities and their symbolic meanings on the one hand malleable and susceptible to change, but on the other hand also shows that this exclusion of certain groups has been happening for decades, and is deeply ingrained in the definition of game heritage.

By examining what kinds of groups get accepted as members of game cultures, we can grasp a better understanding of the power relations involved in defining those groups in the first place. Shaw (2010, 407 - 409) notes how the early history of electronic media is an evolution of technical efficiency, but also an evolution in negotiating cultural and social issues. These issues actually define who can be part of a particular culture and who can speak about its values, and who may not. Retrogaming and game collecting communities are aiming for a very specific idea of what game heritage as one that is based on commercially successful titles and symbolic characters, brands, and platforms. There is also an implicit focus on global game brands and the bestselling and most well-known titles that have been produced by it. The AHD does not tell the whole story, but rather a smoothed out version produced by the retrogaming communities and game journalists. The discourse of game heritage demands that stories related to gender, class, and race are omitted, as well as aspects of labour history etc. (c.f. Smith 2006, 30). There are countless variations of this authorised story, the one where symbolic characters and games are made to stand in for the plethora of games (both commercial and non-commercial), players (class, gender, race), the working conditions of the game industry, as well as the more negative aspects of games and player cultures, told in many collections and museums worldwide.

Game heritage is thus based on the AHD, but it is also replicating it, and the version seen in countless game exhibitions is starting to be naturalised. The fetishizing of the original, reliance on global 'symbolic' brands, characters, platforms, and companies, has resulted in eerily similar game exhibitions worldwide. Thus, the aforementioned Game On left out its more critical components when it became a touring exhibition (Stuckey 2012), which is a decision based not only on technological affordances, but also on curatorial choice. Similarly, Nexon Computer Museum, Stockholm Game Museum, the National Videogame Museum, but also Computerspielemuseum in Germany, ViGaMus in Italy, and the Nostalgia Box in Australia, all 
tell a very similar story of the global game industry and its most well-loved symbolic characters and games. They are all naturalizing the discourse that started with retrogamers, hobbyist collectors, game journalists and game enthusiasts turned museum curators, and it is starting to be difficult to think of game heritage in any other terms than the ones laid out in this AHD.

While the above examples are all professional museums in the sense that they are operating with permanent staff, Wirtala Retro Gaming Museum is another kind of example, which is based entirely on the game collection of a 10-year old boy from rural Finland. What is perhaps most telling here is that all of these have produced very similar exhibitions. While the level of production is of course much more polished in the more professional museums, the actual content and curatorial angle of all of the examples mentioned are very similar. The point here is that when game collectors and members of participatory game heritage networks start dealing with the history and heritage of games, they do so by replicating the discourses set up earlier. When game collectors (be they 10 years old or older) start to deal with game heritage, they are very much focused on the kind of naturalised and tangible heritage that defines the AHD, not by being critical and reflexive of the heritage process.

\section{Participation and reflexivity}

As we have seen, game collectors and amateur museums have internalised the logic of the AHD that has been criticised by the work on critical and intangible heritage. The hobbyists and participant reproduce game heritage with a focus on object rarity, international cultural symbols, and polished products of commercialised game culture, instead of preserving their own experiences, community practices, or local histories. Retrogamers and participatory historians (often middle-aged white males) are the ones who act as gatekeepers maintaining the marginalization of minorities, and this marginalization is being replicated by game museums. Rogue archives and participatory collections are, we argue, thus not a be-all and end-all solution to the imbalance of game heritage. These kinds of participatory actors are inclined to emulate the logics of the AHD of games, and not to provide a more critical and reflexive stance towards collecting.

This happens for many reasons, the main one being that they have internalised the AHD of games and are naturalizing it (Moncunill-Piñas 2017), but also in some cases because of systematic pressure to maintain their business, or because they are making sacred objects (Belk 
1994) and are not interested in understanding their cultural contexts. Thus, amateur game museums and game collectors turned museum curators, are passively receiving the discourse set up by amateur historians, game journalists, and game collectors and passing it on to their heritage work (c.f. Smith 2006, 34). While Smith (2006, 4 - 5) acknowledges how especially heritage institutions in many situations are guarding and replicating authorised heritage instead of providing space for a more inclusive set of cultural actors, in the game heritage formation the actors mostly using their gatekeeping power have this far been hobbyist collectors, game journalists, and the museums that have directly risen out from their activities, not established heritage institutions per se.

\section{Steps forward}

Suominen and Sivula (2016) observe that 'oral and written histories' are produced in three different fields: the academic, the public, and the amateur field. The academic field produces refereed publications based on source criticism, while the public field is a 'politically controlled and publicly funded' process, where the institutionalization of heritage mostly takes place. In the case of games, more power has been in the hands of the third field that is the field of amateurs, which consists of 'individuals and groups of hobbyists, even families, selecting meaningful things from the more or less authentic remains of their pasts' (Suominen and Sivula 2016). For Suominen and Sivula, the three fields are interrelated and interdependent, so an 'amateur may find academic research useful', or 'an academic researcher or a politician may also be an enthusiastic amateur'. These findings are a potential starting point for addressing the problem that amateurs are reproducing the very structures of oppression and exclusion that they were hoped to contest.

As a flipside to this, it needs to be pointed out that as game museums are getting more professional and as established heritage institutions are taking an interest in game heritage, it provides possibilities for reflexive thinking and using the power position of institutions to critically assess what game heritage is. In this endeavour, Suominen and Sivula (201) s6uggest a collaboration of the three fields, which can take a number of forms. Museums can educate and improve amateur led preservation initiatives into taking more critical viewpoints of the kinds of game heritage they are setting up. By sharing their curatorial skills and power, established museums are, ironically, the ones in a position of offering tools for critically analysing the 
heritage work of games, as well as taking a reflexive stance towards the game heritage process. This can be a first step towards helping participatory historians, game collectors, and amateur historians to look at their own lives, histories, and experiences when constructing game heritage.

Maybe the most relevant step forward is to realise that participation and participatory heritage work does not automatically equal the participation of marginalised groups and minorities. As we have seen, encouraging participatory heritage work in combination with games and game culture is no simple or straightforward solution. Participatory heritage work requires a certain level of knowledge about game culture and communities that makes it possible to find, invite, protect, and empower marginalised groups as a central focus for preserving intangible and critical game heritage. The massive differences between different subcultures and groups in the games culture and broader gaming community that were mentioned above as one of the very reasons for the need of intangible game heritage also means that it is easy to miss parts of that game culture when working with hobbyists.

Instead of whitewashing game heritage, there is a need to engage with it critically. As games are included into the hallowed halls of museums, there is an opportunity to engage with their dark heritage, e.g. game addiction, the military-entertainment complex, gender and race representations, exploitation of player creators as well as game workers, and the ways in which some of these issues can be addressed. There are positive examples of including researchers and civil rights activist in the exhibition of problematic games to offer added context while still displaying a part of the dark heritage of games (Nylund 2018, 7). Also here participation of players and enthusiasts does not and cannot work as a one-stop solution, but could even pose a problem, as game collectors and participatory historians need to see beyond a 'naive happiness' of being able to actually preserve and exhibit their favourite hobby in order for them not to replicate the problematic qualities and assumptions that are part of game culture. What is instead needed is a self-reflection and reflexivity about what parts of the hobby should be preserved and how that could be done in an appropriate and ethical manner that includes elements of the hobby that are not familiar to them personally, or ones they would not like to show or contemplate.

This said, we need also to understand that not all game exhibitions recreate and internalised the AHD of games. Rainbow Arcade, a changing exhibition on display at the Schwules Museum in Berlin from 2018 - 2019, dealt explicitly with a queer history of games, while Play Beyond Play at the National Swedish Museum of Science and Technology and 
Videogames: Design/Play/Disrupt at the Victoria and Albert Museum in 2018 - 2019 deal with aspects of problematic gaming and gives a voice to player sensibilities. Similarly, the Finnish Museum of Games deals explicitly with Finnish games and gaming, not only in the field of commercial game development, but also in the vast undergrowth of hobbyist produced games. It also touches upon problematic games, and on games of ethnic minorities. These are some of the first examples of using various kinds of critical frames for expanding our understanding of what game heritage is, by not focusing on the AHD of successful international game brands.

We need to understand that hobbyist collectors and retrogamers are not themselves standing outside of capitalist hegemony, commodified culture, and racism, and sexism. We do need to make sure that the kind of cooperation described by Suominen, Sivula, Garda (2018) stays critical. It is thus important for both participatory game heritage and for traditional heritage institutions involved with games, to be reflexive about what kinds of values they are passing on as game heritage. However, it is central to maintain that this collaboration is not a full solution to the challenge of dismantling the AHD. The positive examples that we have pointed to are taken from liberal institutions in the Nordic Countries and in Germany, where museum professionals can generally be expected to have an interest in introspection and self-reflection, making them more inclined not to act like gatekeepers of heritage, but rather provide critical perspectives when dealing with topics. This means that our approach is based on an assumption of inclusive and democratic institutions and might not work if those are absent or be able to stand up to outside pressure on these institutions. The will for self-critical work and introspection on the side of museum professionals is considerably easier to assume when discussing inclusive game heritage in comparison to the way heritage is used as a legitimization of nation states and colonial land claims in Australia.

\section{Conclusion}

This paper's aim is to combine theoretical perspectives from cultural heritage research and game studies to provide a critical perspective on the cultural heritage process of digital games. The relevant concepts from heritage research used in this paper are intangible and critical heritage, which act as interventions that react against AHD, with the aim to broaden the represented cultural heritage and to refocus it on human culture and shared community practices instead of sanctified objects and justifications of nation-state power. The concepts of intangible and critical 
heritage suggest that the inclusion of players and game communities into the game heritage process could offer a more diverse heritage discourse. Games are in a special situation here because hobbyists, fans, rogue archives, and similar player participants have in the past driven the preservation of game culture, and because their behaviour in itself is documenting and preserving the activity of play.

However, we show how participatory historians, retrogamers, hobbyist collectors, and game journalists reproduce a kind of AHD of games, which yet again builds up symbols and monuments from game characters and brands, instead of being open to more diverse and inclusive heritage constructs. Play, as a form of intangible heritage, is overlooked in most amateur heritage work, which results in 'fetishistic' collections of game rarities and other collector items, instead of collections, which are noted by their openness for dialogue and context information. Thus, participatory practices in collector run game museums tend to produce a version of game heritage, which is implicitly working towards the same kind of onesided understanding of games that has been criticised heavily in game studies lately. Museums and other professional heritage institutions thus need to work towards systematic and reflexive long-term preservation of game heritage in their collections, instead of building an understanding of game heritage based on fetishistic collections of brands and powerful symbols. The critical expertise of various kinds of museum professionals is furthermore needed in order to look beyond an authorised discourse, and start incorporating the varicoloured practices of actual play and play communities into our understanding of game heritage.

\section{Notes}

Triple-A, as in AAA, is an informal classification for digital games which is analogous to the film industry term of 'blockbuster'. Triple-A gamer are produced and distributed by a wellknown publisher and have higher development and marketing budgets.

The Game On and its follow up Game On 2.0 have been on display in institutions as varied as the Helsinki City Art Museum, the Swedish National Museum of Science and Technology, Blooming Investment in Shenzhen, the Science Museum in London, VAM Design Center in Budapest, the Australian Centre for the Moving Image, Melbourne. Game On initially included many features exploring the social condition of games production and reception, which were dropped from touring versions of the exhibition (Stuckey 2012).

Located in Frisco, Texas, the National Videogame Museum was founded with the help of a Kickstarter campaign in 2011, and it is based on the personal collections of its three founders. 
The Nexon Computer Museum, located on Jeju Island in South Korea, is partly funded by South Korean online game developer Nexon, and it deals primarily with international game history.

Stockholm Game Museum is a privately run game museum focusing on playable games. The museum deals with international game history and its symbolic consoles, characters, and brands.

(8) Gamergate refers to a harassment campaign that was mainly conducted through the use of the hashtag \#gamergate. Gamergate is still ongoing (Mortensen 2018), targeting women in gaming and in the games industry.

Rogue archives are understood to cover the practices of nonprofessional archivists, who preserve various forms of media culture, including games, on the Internet (De Kosnik 2016).

But Suminen, Reunanen, and Remes $(2015,77)$ define retrogaming as 'the practice of playing and collecting original ('classic') video and computer games of the 1970s, 1980s, and early 1990s, or using, for instance, emulators for playing them', but also as a cultural form consisting of 'other activities, such as the production of a broad range of consumer products, textiles, accessories, game related music videos, literature as well as various artistic, museum and academic practices, and the online circulation of game-oriented information and discussion'. Retro-gaming thus becomes both a player and consumer stance, but also a cultural production stance which deals with 'aesthetic expression, experiential arts and research, institutional game preservation, discourse of taste'.

\section{Disclosure statement}

No potential conflict of interest was reported by the authors.

\section{Funding}

Olli Sotamaa's work was supported by the Academy of Finland project Center of Excellence in Game Culture Studies (CoE-GameCult, 312395).

\section{Reference}

Aarseth, E. 2007. "I Fought the Law: Transgressive Play and The Implied Player.” In Situated Play: Proceedings of the Third International Conference of DiGRA, edited by A. Baba, 130-133. Tokyo, Japan: University of Tokyo.

Banks, J., and M. Deuze. 2009. “Co-Creative Labour.” International Journal of Cultural Studies 12 (5): 419-431.

Barthes, R. 1977. 'The Death of the Author', In Image, Music, Text. London: Fontana.

Barwick, J., J. Dearnley, and A. Muir. 2011. "Playing Games with Cultural Heritage: A Comparative Case Study Analysis of the Current Status of Digital Game Preservation.” Games and Culture 6 (4): 373-390. 
Belk, R. W., M. Wallendorf, J. Sherry, and M. B. Holbrook. 1991. “Collecting in a Consumer Culture.” In Highways and Buyways, edited by R. W. Belk, 178-215. Provo, UT: Association for Consumer Research.

Belk, R. W. 1994. “Collectors and Collecting.” In Interpreting Objects and Collections, edited by S. M. Pearce, 317-326. London and New York: Routledge.

Carman, J. 2010. “Promotion to Heritage: How Museum Objects Are Made.” Encouraging Collections Mobility: A Way forward for Museums in Europe, edited by S. Pettersson, M. Hagedorn-Saupe, T. Jyrkkiö, and A. Weij, 74-85. Helsinki: Finnish National Gallery.

Coleman, L.-E. S. 2015. “The Socially Inclusive Museum: A Typology Re-imagined.” The International Journal of the Inclusive Museum 9 (2): 41-57.

Consalvo, M. 2017. "When Paratexts Become Texts: De-Centering the Game-as-Text.” Critical Studies in Media Communication 34 (2): 177-183.

De Kosnik, A. 2016. Rogue Archives: Digital Cultural Memory and Media Fandom. Cambridge, MA and London: MIT Press.

De Peuter, G. 2011. “Creative Economy and Labor Precarity: A Contested Convergence.” Journal of Communication Inquiry 35 (4): 417-425.

Delve, J., and D. Anderson (eds.). 2014. Preserving Complex Digital Objects. London: Facet Publishing.

Ermi, L., and F. Mäyrä. 2005. "Fundamental Components of the Gameplay Experience: Analysing Immersion.” In Changing Views - Worlds in Play: Proceedings of the Second International Conference of DiGRA, edited by S. de Castell and J. Jenson, 15-27. Vancouver, Canada: University of Vancouver.

Fuchs, C. 2010. “Labor in Informational Capitalism and on the Internet.” The Information Society 26 (3): 179-196.

Greenhill, E. H. 1992. Museums and the Shaping of Knowledge. London and New York: Routledge.

Guins, R. 2014. Game after: A Cultural Study of Video Game Afterlife. Cambridge, MA and London: MIT Press.

Guttenbrunner, M., C. Becker, and A. Rauber. 2010. “Keeping the Game Alive: Evaluating Strategies for the Preservation of Console Video Games.” International Journal of Digital Curation 5 (1): 64-90.

Hamari, J., and M. Sjöblom. 2017. “What Is ESports and Why Do People Watch It?.” Internet Research 27 (2): 211-232.

Jenkins, H. 2006. Convergence Culture: Where Old and New Media Collide. New York and London: New York University Press.

Jenkins, H., S. Ford, and J. Green. 2018. Spreadable Media: Creating Value and Meaning in a Networked Culture. New York and London: New York University Press.

Kirkpatrick, G. 2012. “Constitutive Tensions of Gaming’s Field: UK Gaming Magazines and the Formation of Gaming Culture 1981-1995.” Game Studies 12 (1).

Kücklich, J. 2005. “Precarious Playbour: Modders and the Digital Games Industry.” Fibreculture 5 (1). 
Lowood, H., D. Monnens, A. Armstrong, J. Ruggill, K. S. McAllister, Z. Vowell, and R. Donahue. 2009. Before It’s Too Late: A Digital Game Preservation White Paper. American Journal of Play 2 (2): 139-166.

MacDonough, K., R. Fraimow, D. Erdman, K. Gronsbell, and E. Titkemeyer. 2016. “On the EVE of Preservation: Conserving a Complex Universe.” In Internet Spaceships are Serious Business: An Introduction to Eve Online, edited by M. Carter, K. Bergstrom and D. Woodford, 210-220. Minneapolis: University of Minnesota Press.

MacLeod, S. 2001. “Making Museum Studies: Training, Education, Research and Practice.” Museum Management and Curatorship 19 (1): 51-61.

Moncunill-Piñas, M. 2017. “The Practice of Everyday Museum Making: Naturalization and Empowerment in the Amateur Consumption of Museographic Language.” European Journal of Cultural Studies. Online First.

Mortensen, T. E. 2018. “Anger, Fear, and Games: The Long Event Of\# GamerGate.” Games and Culture 13 (8): 787-806.

Newman, J. 2009. "Save the Videogame! The National Videogame Archive: Preservation, Supersession and Obsolescence.” M/C Journal 12 (3).

Newman, J. 2011. “(Not) Playing Games: Player-Produced Walkthroughs as Archival Documents of Digital Gameplay.” International Journal of Digital Curation 6 (2): 109-127.

Newman, J. 2012. Best before: Videogames, Supersession and Obsolescence. London and New York: Routledge.

Nylund, N. 2016. “The Early Days of Finnish Game Culture: Game-Related Discourse in Micropost and Floppy Magazine in the Mid-1980s.” Cogent Arts and Humanities 3 (1).

Nylund, N. 2018. “Constructing Digital Game Exhibitions: Objects, Experiences, and Context.” In Arts, 7, 103. Multidisciplinary Digital Publishing Institute.

Parlett, D. 1999. The Oxford History of Board Games. Oxford: Oxford University Press.

Pearce, S. M. 1994. “Collecting Reconsidered.” In Interpreting Objects and Collections, edited by S. M. Pearce, 193-204. London and New York: Routledge.

Pinchbeck, D., D. Anderson, J. Delve, G. Alemu, A. Ciuffreda, and A. Lange. 2009. "Emulation as a Strategy for the Preservation of Games: The KEEP Project.” In Breaking New Ground: Innovation in Games, Play, Practice and Theory: Proceedings of DiGRA. London: Brunel University.

Postigo, H. 2016. “The Socio-Technical Architecture of Digital Labor: Converting Play into YouTube Money.” New Media and Society 18 (2): 332-349.

Prax, P. 2016. “Co-Creative Game Design as Participatory Alternative Media.” PhD Thesis. Uppsala: Acta Universitatis Upsaliensis.

Prax, P., B. Sjöblom, and L. Eklund. 2016. “GameOff: Moving Beyond the 'Original Experience’ in the Exhibition of Games.” SIRG Research Reports 2016: 1-17.

Severo, M., and T. Venturini. 2016. "Intangible Cultural Heritage Webs: Comparing National Networks with Digital Methods.” New Media and Society 18 (8): 1616-1635. 
Shaw, A. 2010. "What Is Video Game Culture? Cultural Studies and Game Studies.” Games and Culture 5 (4): 403-424.

Sicart, Miguel. 2014. Play Matters. Cambridge, MA and London: MIT Press.

Sjöblom, M., M. Törhönen, J. Hamari, and J. Macey. 2019. “The Ingredients of Twitch Streaming: Affordances of Game Streams.” Computers in Human Behavior 92: 20-28.

Sköld, O. 2013. "Tracing Traces: A Document-Centred Approach to the Preservation of Virtual World Communities.” In Information Research 18 (3).

Sköld, O. 2018. “Understanding the ‘Expanded Notion’ of Videogames as Archival Objects: A Review of Priorities, Methods, and Conceptions.” Journal of the Association for Information Science and Technology 69 (1): 134-145.

Smith, L. 2006. Uses of Heritage. London and New York: Routledge.

Smith, L., and N. Akagawa. 2008. Intangible Heritage. London and New York: Routledge.

Sotamaa, O. 2007. “On Modder Labour, Commodification of Play, and Mod Competitions.” First Monday 12 (9).

Sotamaa, O. 2009. The Player's Game: Towards Understanding Player Production among Computer Game Cultures. PhD Thesis. Tampere: Tampere University Press.

Stuckey, H. 2012. "Mods and Museums: Gaming the Future of Art and Institutions.” In Game Masters: The Exhibition, edited by E. McRae. Melbourne: Australian Centre for the Moving Image.

Stuckey, H., N. Richardson, M. Swalwell, and D. de Vries. 2015. "What Retrogamers Can Teach the Museum.” MWA2015: Museums and the Web Asia 2015, Melbourne, Australia, 5-8 October 2015.

Stuckey, H., M. Swalwell, and A. Ndalianis. 2013. "The Popular Memory Archive: Collecting and Exhibiting Player Culture from the 1980s.” In Making the History of Computing Relevant, IFIP WG 9.7 International Conference: Revised Selected Papers, edited by A. Tatnall, T. Blyth, R. Johnson, 215-225. Berlin, Heidelberg, and New York: Springer.

Suominen, J. 2011. "Game Reviews as Tools in the Construction of Game Historical Awareness in Finland, 1984-2010: Case MikroBitti Magazine.” In Think Design Play: Proceedings of DiGRA 2011 Conference. Hilversum: Utrecht School of the Arts.

Suominen, J., M. Reunanen, and S. Remes. 2015. "Return in Play: The Emergence of Retrogaming in Finnish Computer Hobbyist and Game Magazines from the 1980s to the 2000s.” Kinephanos, Special Issue (June 2015), 76-102.

Suominen, J., and A. Sivula. 2016. "Participatory Historians in Digital Cultural Heritage ProcessMonumentalization of the First Finnish Commercial Computer Game.” Refractory - Australian Journal of Entertainment Media, vol. 27.

Suominen, J., A. Sivula, and M.B. Garda. 2018. “Incorporating Curator, Collector and Player Credibilities. Crowdfunding Campaign for The Finnish Museum of Games and The Creation of Game Heritage Community.” Kinephanos, Special Issue (August 2018), 174-196. 
Swalwell, M. 2013. "Moving on from the Original Experience: Games History, Preservation and Presentation.” In DeFragging Game Studies. Proceeding of DiGRA 2013. Atlanta: Georgia Institute of Technology.

Swalwell, M., A. Ndalianis, and H. Stuckey. (eds.) 2017. Fans and Videogames: Histories, Fandom, Archives. London and New York: Routledge.

Taylor, T. L. 2009. Play between Worlds: Exploring Online Game Culture. Cambridge, MA and London: MIT Press.

UNESCO, ICH. 2003. "Text of the Convention for the Safeguarding of the Intangible Cultural Heritage." UNESCO, Paris, 17 October 2003. 